\title{
Antimyelin antibody in multiple sclerosis: no change during immunosuppression
}

\author{
L . D . W I L K E R S O N, R. P . L I S A K, B. Z W E I M A N, A N D \\ D. H. S I L B E R B E R G
}

From the Departments of Neurology and Medicine, Allergy and Immunology Section, University of Pennsylvania School of Medicine, and the Multiple Sclerosis Research Center of the University of Pennsylvania and Wistar Institute, Philadelphia, Pennsylvania, USA

S UMMARY We studied retrospectively levels of antimyelin antibody in a group of 13 multiple sclerosis patients who underwent a clinical trial of long-term, high dose $(2.0-4.5 \mathrm{mg} / \mathrm{kg} / \mathrm{day})$ azathiaprine therapy. In apparent contrast with collagen vascular disease associated with antitissue antibody, azathiaprine therapy was not associated with significant change in titres of antimyelin antibody. Variation of titre of antimyelin antibody in apparent association with disease activity continued during therapy. No significant changes occurred in levels of serum immunoglobulins.

Humoral immune responses to nervous system constituents such as myelin have been demonstrated in several nervous system diseases, especially multiple sclerosis. An indirect immunofluorescent technique for demonstrating serum immunoglobulin binding to myelin and glial cells was first reported by Allerand and Yahr (1964). Subsequently Edgington and D'Alessio (1970) used a similar technique to show significantly higher titres of myelin binding activity in sera of multiple sclerosis patients than in sera of normal subjects. Work here (Lisak et al., 1975) confirmed the significant increase of myelin affinity in multiple sclerosis sera and further suggested an increase in this immunoglobulin activity corresponding to an increased disease activity, inferred by group data as well as several serial, longitudinal observations of individual patients.

Recently Silberberg et al. (1973) reported on the failure of azathiaprine induced immunosuppression to alter significantly the clinical course of multiple sclerosis patients. Because the experience

Presented in part at the Federation of American Societies for Experimental Biology, April 1975.

Supported in part by USPHS Grants 5 PO1 NS11037-03, 5 KO7NS11061-04, 5 TO1 A1-00319, and the National Multiple Sclerosis Society Grant 894-A-3.

Address for reprint requests: L. Douglas Wilkerson, Department of Neurology, Hospital of the University of Pennsylvania, 3400 Spruce Street, Philadelphia, Pennsylvania 19104, USA.

Accepted 29 March 1977 with immunosuppressive agents used in several diseases associated with anti-tissue antibodies has been of depression of such antibody (Levin et al., 1964; Swanson and Schwartz, 1967), we studied retrospectively the pattern of antimyelin antibody during the course of treatment in the group of multiple sclerosis patients reported by Silberberg et al. (1973). We report these results as further evidence of the failure of induced immunosuppression to influence the course of multiple sclerosis.

\section{Patients and methods}

Sera obtained from a group of multiple sclerosis patients before, during, and after a clinical trial of azathiaprine, $2.0-4.5 \mathrm{mg} / \mathrm{kg} / \mathrm{day}$, were coded and stored at $-70^{\circ} \mathrm{C}$ until used in blind analysis. Samples were obtained at predetermined intervals independent of clinical status. The clinical characteristics and outcome of the group were reported earlier (Silberberg et al., 1973).

Serum immunoglobulin $\mathrm{G}$ (IgG) was assayed by radial immunodiffusion (Mancini et al., 1965) on commercially available plates (Meloy Laboratories). Indirect assay of antimyelin antibody was performed by a modification of the technique of Edgington and D'Alessio (1970) as detailed by Lisak et al. (1975), using freshly cut sections of guinea pig spinal cord embedded in OCT (Ames). After acetone fixation for three minutes and two 
washings in phosphate buffered saline (PBS; pH 7.8), an individual section was incubated for 30 minutes in a humid chamber with one of a series of twofold dilutions of a test serum in PBS, then washed again. Sections were then incubated under similar conditions with fluorescein-conjugated goat anti-human immunoglobulin (Hyland Laboratories) which had been freshly absorbed with human myelin (a gift from Dr David Pleasure) and diluted in PBS and Evans blue dye. After the final washing sections were mounted in buffered glycerol and examined for fluorescence using an Olympus Vanox darkfield microscope with B-1 excitor filter and 515 barrier filter. The antimyelin antibody titre of a particular serum was the highest dilution showing unequivocal myelin ring fluorescence.

Isohaemagglutinin titres were determined on coded specimens by standard techniques in the Pepper Clinical Laboratory of the Hospital of the University of Pennsylvania.

\section{Results}

Thirteen patients were studied before and during azathiaprine therapy. Except for one patient, who left the study at his own request after three months, all completed at least six months of therapy. There were an average of six observations per patient of antimyelin antibody and serum IgG concentration.

The mean titres of antimyelin antibody for the group in sequentially obtained specimens are shown in Table 1. Group mean titre obtained at the respective treatment intervals did not differ significantly from that obtained before treatment, nor was there significant difference between group mean titre obtained just before cessation of azathiaprine therapy and that obtained two months afterward. Antimyelin antibody titres and isohaemagglutinin titres were not related, and the latter showed no significant change during therapy.

Comparison of the clinical courses and sequential antimyelin antibody titres in individual patients during azathiaprine therapy showed a pattern in all but two patients similar to that reported previously in a small group of untreated patients with multiple sclerosis (Lisak et al., 1975), titres tending to be raised during times of apparent increased activity of the disease.

The mean serum IgG before azathiaprine was $14.69 \mathrm{~g} / 1$ which is slightly, but not significantly higher than the established mean for normals $(10.55 \mathrm{~g} / \mathrm{l})$ in our laboratory (Lisak and Zweiman, 1975). Sequential values for group mean serum IgG levels (Table 2) showed no significant change during azathiaprine therapy and no consistent pattern was seen in sequential studies of individual patients. For example, of five patients having raised baseline IgG levels $(17.0 \mathrm{~g} / \mathrm{l})$ there was a decrease to normal values in two and no significant change in the other three. Two patients with normal pre-treatment IgG levels each manifested a transient rise to elevated levels during treatment.

There was no correlation between serum IgG levels and antimyelin antibody titres either for serial measurements in individual patients or for the group. In individual patient series the sequential values of serum IgG often varied in the direction opposite to any change in antimyelin antibody titre.

Table 2 Group mean IgG levels before and during azathiaprine therapy

\begin{tabular}{|c|c|c|c|c|c|}
\hline & $\begin{array}{l}\text { Pre- } \\
\text { treatment }\end{array}$ & $2-3 \mathrm{mo}$ & s-7 mo & $8-9 \mathrm{mo}$ & $11-13 \mathrm{mo}$ \\
\hline $\begin{array}{l}\text { Mean }(g / l) \\
\text { SEM }\end{array}$ & $\begin{array}{r}14.69 \\
1.39\end{array}$ & $\begin{array}{r}14.73 \\
1.37\end{array}$ & $\begin{array}{r}13.86 \\
1.34\end{array}$ & $\begin{array}{r}14.53 \\
1.57\end{array}$ & $\begin{array}{r}11.35 \\
1.15\end{array}$ \\
\hline
\end{tabular}

\section{Discussion}

There is dispute as to whether myelin binding by serum immunoglobulin represents antibody activity. Several investigations (Edgington and D'Alessio, 1970; Lisak et al., 1975) have shown characteristics of this reaction that are similar to those of antibodies. For example, the reaction is blocked by previous exposure of the tissue substrate to experimentally induced rabbit antimyelin antiserum but not by normal rabbit serum (Lisak et al., 1975). This would suggest specific binding by the Fab portion of the immunoglobulin molecule in the multiple sclerosis sera studied. On the other hand, there is evidence for some non-specific binding by the Fc portion

Table 1 Antimyelin antibody before, during, and after azathiaprine therapy

\begin{tabular}{llllll}
\hline & Pre-treatment & $2-3$ mo & $5-7$ mo & $8-9$ mo & Post-treatmert \\
\hline Mean $\log _{2}$ antimyelin & 2.90 & 2.56 & 3.07 & 3.81 & 3.00 \\
SEM & 0.34 & 0.49 & 0.27 & 0.51 & 0.57 \\
\hline
\end{tabular}


of the immunoglobulin molecule in normal sera (Aarli et al., 1975). These sets of observations do not imply mutually exclusive propositions. Regardless, independent studies (Edgington and D'Alessio, 1970; Lisak et al., 1975) show increase in activity of this tentative antibody in patients with demyelinative disease and, possibly, a direct association of active disease phases with higher titres.

Data presented here show that continued fluctuations of levels of antimyelin antibody occur despite azathiaprine treatment, and that these fluctuations tend to correlate with periods of disease quiescence and activity. This observation appears in striking contrast to the situation of anti-tissue antibodies in collagen vascular diseases in which azathiaprine induced immunosuppression typically is associated with a diminution of antitissue antibody levels before or even without clinical improvement (Swanson and Schwartz, 1967; Levin et al., 1964). Therefore, it appears that azathiaprine treatment not only failed to alter the clinical course but also failed to alter what tentatively appears to be an immunological parameter. Relegation of this observation to a difference in the nature or quality of immunosuppression induced in the group is not likely although the present group is unique for the long-term use of a single agent in non-debilitated patients.

Explanation of the apparent resistance of antimyelin antibody to azathiaprine induced immunosuppression may lie with a difference between primary and secondary responses in sensitivity to immunosuppression. In several studies (Swanson and Schwartz, 1967; Levin et al., 1964; Davis et al., 1972) azathiaprine and related agents have suppressed responses to newly met antigens, primary responses, more than levels of previously existing antibody. As reported by Zweiman et al. (1973), similar effects of azathiaprine treatment were seen in this group with marked reduction in delayed hypersensitivity responses to newly met antigens and occasional, milder reductions of delayed hypersensitivity responses to previously acquired antigens. There was no reduction in humoral responses to previously met antigens. Finding of low levels of antimyelin antibody in many normal sera (Edgington and D'Alessio, 1970; Lisak et al., 1975) suggest that immune reactivity against myelin has commonly occurred early in postnatal life and its fluctuations might be similar to secondary responses.

A small number of patients with multiple sclerosis have mildly raised serum immunoglobulin levels (Link and Muller, 1971; Kabat et al., 1950) so that finding of slight elevation of the group mean IgG is not surprising in a small group. This level remained unchanged during immunosuppression as previously reported (Davis et al., 1972; Jones et al., 1975).

The authors wish to acknowledge the expert technical assistance of Mrs Maryam A. Khatami, Marilyn Ludwick, and Ms Sandra Dadura, as well as the gift of myelin from Dr David Pleasure.

\section{References}

Aarli, J. A., Aparicio, S. R., Lumsden, C. E., and Tönder, O. (1975). Binding of normal human IgG to myelin sheaths, glia and neurons. Immunology, 28, 171-185.

Allerand, D., and Yahr, M. D. (1964). Gammaglobulin affinity for normal tissue of central nervous system. Science, 144, 1141.

Davis, L. E., Hersh, E. M., Curtis, J. E., Lynch, R. E., Ziegler, D. K., Neumann, J. W., and Chin, T. D. Y. (1972). Immune status of patients with multiple sclerosis. Neurology (Minneapolis), 22, 989-997.

Edgington, T. S., and D'Alessio, D. H. (1970). The assessment by immunofluorescent methods of humoral antimyelin antibodies in man. Journal of Immunology, 105, 248-255.

Jones, V. E., Lance, E. M., Abbosh, J., and Graves, H. E. (1975). Intensive immunosuppression in patients with disseminated sclerosis. Clinical and Experimental Immunology, 21, 13-22.

Kabat, E. A., Freedman, D. A., Murray, J. P., and Knaub, V. (1950). A study of the crystalline albumin gammaglobulin and total proteins in the cerebrospinal fluid of one hundred cases of multiple sclerosis and in other diseases. American Journal of Medical Science, 219, 55-64.

Levin, R., Landy, M., and Frei, E. (1964). The effect of 6-mercaptopurine on immune response in man. New England Journal of Medicine, 271, 16-21.

Link, H., and Muller, R. (1971). Immunoglobulins in multiple sclerosis and infections of the nervous system. Archives of Neurology (Chicago), 25, 326344.

Lisak, R. P., and Zweiman, B. (1975). Serum immunoglobulin levels in myasthenia gravis, polymyositis and dermatcmyositis. Journal of Neurology, Neurosurgery, and Psychiatry, 39, 34-37.

Lisak, R. P., Zweiman, B., and Norman, M. (1975). Immunofluorescent demonstration of antimyelin antibodies in neurologic disease. Archives of Neuro$\operatorname{logy}$ (Chicago), 32, 163-167.

Mancini, G., Carbonara, A. O., and Heremans, J. F. (1965). Immunochemical quantitation of antigens by single radial immunodiffusion. Immunochemistry, 2, 235-254.

Silberberg, D. H., Lisak, R. P., and Zweiman, B. (1973). Multiple sclerosis unaffected by azathiaprine in pilot study. Archives of Neurology (Chicago), 28, 210-212. 
Swanson, M. A.. and Schwartz, R. S. (1967). Immunosuppressive therapy: The relation between clinical response and immunologic competence. New England Journal of Medicine, 277, 163-169.
Zweiman, B., Lisak, R. P., and Silberberg, D. H. (1973). Effect of azathiaprine on the immune response in patients with multiple sclerosis. Neurology (Minneapolis), 33, 397. 